\title{
Assesmen Pembelajaran Di Raudhotul Athfal Baitur-Rahmah Sawitsari Sleman
}

\author{
Ahmad Ichsan Yafi Hutagalung', Lu'lu'ul Ilmi² \\ 1 UIN Sunan Kalijaga Yogyakarta, Sleman, Indonesia, Email: \\ achmadichsan179@gmail.com \\ 2 Universitas Negeri Yogyakara, Sleman, Indonesia, Email: luluulilmi@gmail.com
}

\begin{abstract}
ABSTRAK
Penelitian ini bertujuan untuk mengetahui asesmen pembelajaran di RA Baitur-Rahmah Sawitsari Sleman. Penelitian ini menggunakan metode penelitian deskriptif kualitatif. Data dikumpulkan melalui observasi, wawancara, dan dokumentasi, kemudian data tersebut dianalisis dengan cara mereduksi data, menyajikan data, dan memverifikasi data. Hasil penelitian ini menunjukkan model pembelajaran di kelas RA Baitur-Rahmah menggunakan sistem kelompok dengan sudut pengaman yang berdasarkan tema, asesmen kelas dilaksanakan dengan dua guru yang memiliki tugas yang berbeda-beda, laporan penilaian terdiri dari laporan harian, mingguan, bulanan, dan semester.

Kata Kunci : Assesmen Pembelajaran, Anak Usia Dini
\end{abstract}

\begin{abstract}
His research study to study learning assessment in RA Baitur-Rahmah Sawitsari Sleman. This research uses descriptive qualitative research methods. Data is collected through observation, interviews, and documentation, then the data is analyzed by reducing data, presenting data, and verifying data. The results of this study indicate the learning model in the RA Baitur-Rahmah class uses a group system with a security perspective that uses themes, classroom assessments are carried out with two teachers who have different assignments, reporting according to daily, weekly, monthly, and semester reports.
\end{abstract}

Keywords: Learning Assessment, Early Childhood

Article History:

Received : 05-09-2018

Revised : 17-02-2020

Accepted : 07-02-2020

kemampauan yang dimiliki anak dapat dikembangkan, seperti: motorik halus, motorik kasar, bahasa, kognitif, agama dan moral, sosial-emosional dan seni. Salah satunya adalah dengan

\section{PENDAHULUAN}

Pendidikan usia dini merupakan masa yang sangat penting dalam menentukan perkembangan anak seumur hidup. Pada masa ini berbagai 
Al-Mudarris : Jurnal Ilmiah Pendidikan Islam Vol. 2, No. 1, Mei 2019, pp. 61-72

belajarnya secara optimal (Zainal Arifin, 2012 : 4).

Acuan untuk mengetahui pengoptimalan perkembangan anak dilakukan dengan memberi asesmen kepada masing-masing anak. Asesmen untuk anak usia dini sangat penting untuk dilakukan, agar mengetahui sampai sejauh mana perkembangan setiap anak. Selain itu, dengan asesmen ini juga dapat mengetahui tentang keterlambatan-keterlambatan atau kebutuhan khusus perkembangan anak sehingga pendidik ataupun orang tua selalu siap untuk menstimulus kembali.

Asesmen setiap anak pasti memiliki perbedaan dan mustahil sama setiap anak. Oleh karena itu, pada paper ini menjelaskan asesmen pembelajaran pada RA Baitur-Rahmah Sawitsari, Sleman.

\section{METODE}

Metode penelitian yang digunakan adalah deskriptif kualitatif. Subjek penelitian ini adalah kepala sekolah, guru, dan
p-ISSN: 2622-1993 e-ISSN: 2622-1586

menyusun kegiatan pembelajaran yang disesuaikan dengan tahap perkembangan anak.

Pencapaian perkembangan anak dapat diketahui melalui penilaian atau asesmen (Trianto, 2011: 276). Penilaian merupakan pengumpulan informasi untuk menentukan kualitas dan kuantitas belajar peserta didik. Dalam penilaian dapat terjadi pengumpulan informasi tentang berbagai hal yang terkait dengan pencapaian peserta didik melalui berbagai bentuk penilaian baik tes maupun non tes. Penilaian harus dipandang sebagai salah satu faktor penting yang menentukan keberhasilan proses dan hasil belajar. Kegiatan penilaian harus dapat memberikan informasi kepada guru untuk meningkatkan kemampuan mengajarnya dan membantu peserta didik mencapai perkembangan peserta didik RA Baitur-rahmah Sawitsari, Condongcatur, Sleman. Teknik pengumpulan data menggunakan observasi partisipasi pasif, wawancara semi 
Al-Mudarris : Jurnal Ilmiah Pendidikan Islam Vol. 2, No. 1, Mei 2019, pp. 61-72

terstruktur, dan dokumentasi. Adapun analis data menggunakan model Miles Huberman, yakni: reduksi data, penyajian data dan penarikan kesimpulan/verifikasi. Uji keabsahan data menggunakan triangulasi sumber dan triangulasi teknik.

\section{HASIL DAN PEMBAHASAN}

\section{A.Pembelajaran RA Baitur- Rahmah}

Pembelajaran adalah serangkaian kegiatan yang melibatkan informasi dan lingkungan yang terencana untuk mempermudah siswa dalam belajar. Dalam kata lain pembelajaran merupakan upaya pendidik dalam membantu siswa agar mendapatkan pengetahuann dan mempermudah

pencapaian tujuan pembelajaran itu sendiri (Jamil Suprihatiningrum, 2013: 75). Pembelajaran merupakan penyiapan suatu kondisi agar terjadinya belajar. Pembelajaran merupakan
p-ISSN: 2622-1993

e-ISSN: 2622-1586

upaya logis yang didasarkan pada kebutuhan-kebutuhan belajar anak. Pembelajaran akan sangat bergantung pada pemahaman guru tentang hakikat anak sebagai peserta atau sasaran belajar. Dengan demikian pembelajaran sifat khas dengan karakteristik dan kebutuhan anak yang dilayaninya (Rita Maryana dkk, 2013: 85). Pembelajaran merupakan suatu kombinasi yang tersusun meliputi unsurunsur manusiawi, material, fasilitas, perlengkapan dan prosedur yang saling berpengaruh dalam rangka mencapai tujuan dari pembelajaran

(Oemar Hamalik, 2003).

Model pembelajaran di kelas menggunakan sistem kelompok dengan sudut pengaman. Pembelajaran pada RA Baitur Rahmah juga merupakan pembelajaran berbasis tematik atau pembelajaran yang menggunakan tema-tema sesuai dengan prinsip 
Al-Mudarris : Jurnal Ilmiah Pendidikan Islam Vol. 2, No. 1, Mei 2019, pp. 61-72

pembelajaran anak usia dini. Pada kesehariannya, tiap pagi anak akan diawali dengan doa, hafalan surah pendek, hafalan doa sehari-hari. Pada saat yang sama, ada juga pengenalan sekaligus penghafalan asmaul husna disertai dengan adab. Pengajaran adab tersebut tertuju pada orang tua, teman, lingkungan, sesuai dengan jadwal atau rangkaian yang telah dibuat guru kelas.

Setelah kegiatan awal, maka akan dilakukan pengulasan materi yang telah lalu guna untuk menambah ingatan anak, kemudian anak akan diberikan pemicu untuk membahas tema yang akan dibawakan pada hari itu. Dalam hal ini, tanya jawab atau diskusi antara guru dengan anak selama lebih kurang 45 menit. Setelah diskusi tersebut, maka akan memasuki kegiatan inti sesuai dengan tema pada hari itu.

Pada kegiatan inti, terdapat empat kegiatan yang
p-ISSN: 2622-1993

e-ISSN: 2622-1586

disediakan oleh guru dengan adanya pengaman (pengamatan/pengawasan langsung dari guru). Hal yang pertama dilakukan oleh guru adalah memberikan arahan atau aturan main pada kegiatan yang akan dilakukan oleh anak. Anak bisa memilih salah satu kegiatan yang diminati olehnya, namun, anak harus mengikuti keempat kegiatan yang telah disediakan oleh guru. Setelah kurang lebih satu jam untuk kegiatan-kegiatan tersebut, maka setelah itu anak dibebaskan untuk mencoba kembali atau bermain dengan sesukanya dengan sudut pengaman. Kemudian, setelah kegiatan-kegiatan selesai atau anak tidak lagi bermain dengan kegiatan yang disediakan oleh guru, maka anak akan diberikan waktu istirahat selama 15 menit. Perlu diketahui bahwasanya pada setiap kegiatan inti pada hari-hari lainnya akan diselingi pengenalan 2 huruf 
Al-Mudarris : Jurnal Ilmiah Pendidikan Islam Vol. 2, No. 1, Mei 2019, pp. 61-72

hijaiyah guna untuk membiasakan mengenalnya dengan menyebutkan bacaan kemudia diikui oleh anak, kemudian anak akan ditanya kembali huruf tersebut.

Pada jam istirahat, anak bebas melakukan kegiatannya masing-masing, namun dalam hal ini lebih memberikan anak waktu untuk memakan bekalnya masing-masing. Setelah jam istirahat merupakan kegiatan penutup dimana anak kembali ke tempatnya masing-masing untuk bertatap muka dan berkomunikasi dengan guru untuk melakukan recalling atau mengulas kembali materi-materi yang telah diajarkan mulai dari hafalan, sampai pada kegiatan inti tersebut. Pada kegiatan penutup juga diberikan tambahan dari guru terkait dengan tema yang akan dibawakan untuk hari esoknya, guna untuk memancing rasa semangat anak untuk sekolah.
p-ISSN: 2622-1993

e-ISSN: 2622-1586

\section{B. Asesmen RA Baitur-Rahmah}

\section{Asesmen Autentik}

Asesmen autentik ini muncul pada awal tahun 1990 an sebagai wujud ketidak puasan para ahli terhadap kelemahankelemahan tes objektif, terutama untuk menilai kemampuan kognitif tingkat tinggi dalam melakukan melakukan sesuatu dikehidupan yang sesungguhnya atau real word setting (A.Muri Yusuf, 2015: 92). Autentik asesmen merupakan penilaian yang dinamis yang dapat menyediakan informasi yang tepat dan terpercaya tentang anak, orangtua, pengusuh dan para guru anak usia dini. Autentik asesmen dapat digunakan untuk memahami bagaimana anak dapat memahami dan menggunakan apa yang telah mereka pelajari berdasarkan pengalaman yang mereka peroleh secara 
Al-Mudarris : Jurnal Ilmiah Pendidikan Islam Vol. 2, No. 1, Mei 2019, pp. 61-72

bermakna. Kebermaknaan belajar termasuk prestasi dan kecerdasan yang diraih secara sukses atas keikutsertaan dorongan orang tua (Harun Rasyid, 2014: 734).

\section{Ciri-ciri}

Asesmen

\section{Autentik}

a. Real-life dan on going

Peserta didik dapat terlibat secara langsung pada tugas-tugas yang nyata dalam kehidupan, menampilkan unjuk kerja/kinerja atau melakukan pemecahan masalah di lapangan.Sehingga asesmen autentik ini menuntut peserta didik untuk melakukan demonstrasikan, menciptakan atau mengerjakan tugas dalam kehidupan yang nyata (Harun Rasyid, 2014: 292). Sejak Awal peserta didik mengerti kriteria yang akan digunakan dalam
p-ISSN: 2622-1993 e-ISSN: 2622-1586

menilai tugas mereka (Harun Rasyid, 2014: 292).

b. Valid dan Reliebel

Instrumen yang

digunakan bertul-betul dirancang berdasarkan target belajar, tujuan dan kompetensi serta sesuai dengan karakteristik materi pelajaran yang diberikan atau pengalaman belajar yang telah berlangsung. Kritik dan saran tentang instrument penilaian dilakukan sebelum pembelajaran berlangsung yang kemudian akan disempurnakan sesuai kebutuhan (Harun Rasyid, 2014: 292).

c. Peserta didik menstruktur dan mengonstruksi sendiri tugasnya

Artinya, peserta didik diberikan tugas tertentu agar peserta didik dapat mengerjakan tugasnya 
Al-Mudarris : Jurnal Ilmiah Pendidikan Islam Vol. 2, No. 1, Mei 2019, pp. 61-72

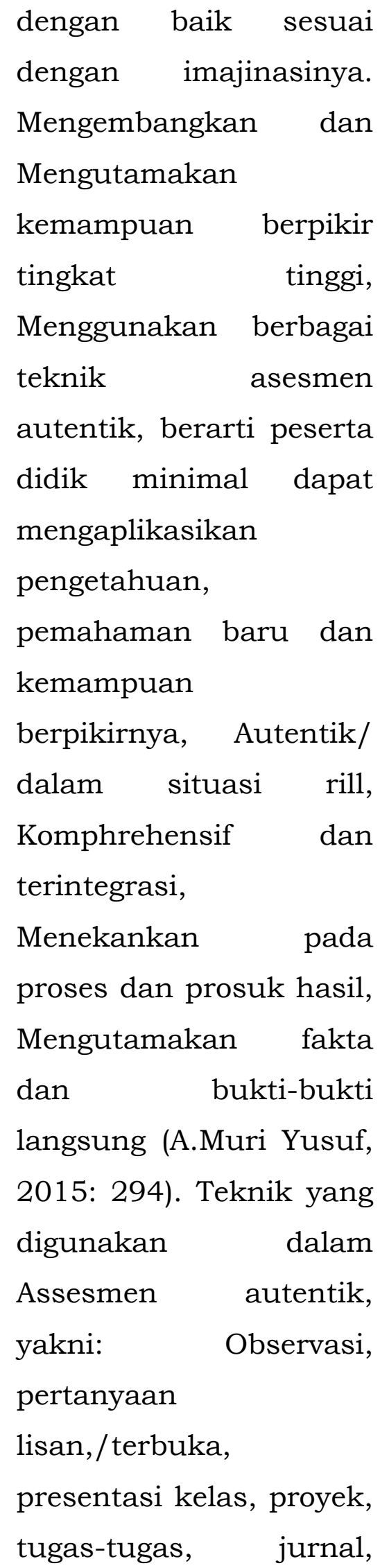

p-ISSN: 2622-1993

e-ISSN: 2622-1586

kerja

kelompok,

portofolio, rubric, interview, kelompok terfokus, tes unjuk kerja, percobaan/ demontrasi, debat/ diskusi, peta konsep, ekshibisi, dan poster.

d. Asesmen autentik pada RA Baitur-Rahmah sudah diterapkan oleh para guru.

Dalam hal ini, guru dalam kelas sejumlah dua orang memiliki pekerjaan yang berbeda. Guru pertama melakukan asesmen dengan melihat produk yang telah dihasilkan oleh anak sesuai dengan indikator penilaian yang telah disediakan guru pada masing-masing kegiatan anak. Sedangkan guru kedua memiliki tugas untuk melihat bagaimana anak mengerjakan tugas tersebut, dengan artian, guru kedua bertugas 
Al-Mudarris : Jurnal Ilmiah Pendidikan Islam Vol. 2, No. 1, Mei 2019, pp. 61-72

melihat proses anak mengerjakan kegiatan tersebut.

\section{Assesmen Unjuk Kerja}

Assesmen unjuk kerja merupakan asesmen yang dilakukan pendidik/ guru dengan mengamati kegiatan peserta didik dalam melakukan suatu tugas. Asesmen ini lebih diarahkan untuk menilai ketercapaian kompetensi yang menuntut peserta didik melakukan suatu tugas (A.Muri Yusuf, 2015: 296).

\section{Karakteristik Assesmen Unjuk Kerja}

Karakteristik asesmen

unjuk kerja tidak jauh beda dengan asesmen autentik, dengan ciri sebagai berikut:

a)menyusun respon sendiri, b)berpikir pada tingkat yang lebih tinggi, c)keautentikan tugas-tugas, d)proses dan produk, e)mengutamakan kedalam bukan keluasan.
p-ISSN: 2622-1993 e-ISSN: 2622-1586

\section{Asesmen Pembelajaran RA Baitur-rahmah}

Asesmen pembelajaran RA Baitur-rahmah terbagi menjadi empat laporan, yakni: harian, mingguan, bulanan dan semester. Rentang nilai yang tercantum di dalam laporan adalah A, B, C, dan D. Namun, pada hasil akhir penilaian akan diberikan keterangan berikut yaitu: Belum Berkembang (BB); Mulai Berkembang (MB); Berkembang Sesuai Harapan (BSH); dan Berkembang Sangat Baik (BSB) guna untuk memberikan narasi yang memudahkan orang tua untuk membacanya. Asesmen harian merupakan penilaian kegiatan pembelajaran anak yang dicatat setiap hari. Indikator penilaian harian mengacu pada enam aspek perkembangan anak yang sesuai dengan peraturan pemerintah dan sesuai dengan usia anak, sehingga mulai tahap penilaian harian sudah tertera akan kompetensi dasar 
Al-Mudarris : Jurnal Ilmiah Pendidikan Islam Vol. 2, No. 1, Mei 2019, pp. 61-72

sesuai dengan capaian anak. Terkait dengan kompetensi dasar, buku penilaian harian pada guru terdiri dari 2 buah buku, yang pertama merupakan penilaian yang berisikan kolom-kolom untuk menulis rentang nilai tersebut, dan yang kedua adalah buku dengan kompetensi dasar dengan tabel yang berisikan kolom pada anak-anak yang sudah mencapai kompetensi tersebut. Asesmen mingguan merupakan kumpulan dari nilai yang didapat pada penilaian harian anak. Dalam hal ini, kumupulan nilai tersebut dirata-ratakan sehingga akan dapat memberikan satu nilai untuk asesmen mingguannya, dan disertakan dengan kompetensi dasar sesuai dengan capaian anak seperti buku kedua pada penilaian harian. Asesmen bulanan merupakan kumpulan nilai dari penilaian mingguan, dan teknis pengambilan nilai sama halnya dengan asesmen
p-ISSN: 2622-1993

e-ISSN: 2622-1586

mingguan. Namun, dalam penilaian bulanan, kompetensi dasar lebih banyak dimuat karena pada satu bulan membawakan tema yang lebih dari satu jenis. Pada asesmen bulanan juga sudah lebih terperinci untuk aspek perkembangannya, seperti diberikan kolom keenam aspek perkembangannya, kemudian diberikan kompetensi dasanya. Hal ini dibuat untuk memberikan kemudahan guru untuk membaca dan mengetahui aspek-aspek apa saja yang belum berkembang pada anak. Sehingga, guru dapat mencari cara untuk menanganinya. Asesmen semester merupakan kumpulan data dari penilaian bulanan. Dalam hal ini, teknisnya sama dengan asesmen bulanan. Berikut Bentuk Laporan Penilaian Harian: 
Al-Mudarris : Jurnal Ilmiah Pendidikan Islam Vol. 2, No. 1, Mei 2019, pp. 61-72

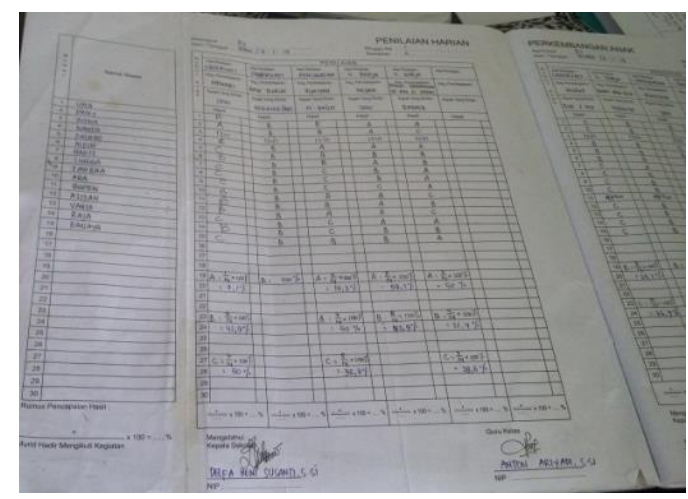

Gambar 1 Laporan Penilaian Harian Gambar 1 menjelaskan bahwa laporan harian di RA Baitur-rahmah menggunakan model skala rubrik, dimana $\mathrm{A}$ sama dengan Berkembang Sangat Baik (BSB), B sama dengan Berkembang Sesuai Harapan (BSH), C sama dengan Mulai Berkembang (MB), dan D sama dengan Belum Berkembang (BB). Bentuk laporan penilaian terbagi menjadi dua, gambar yang sebelah kiri adalah laporan secara rinci tentang kegiatan peserta didik, yang tediri dari unjuk kerja, portofolio, penugasan, hasil karya anak. Kemudian gambar yang sebelah kanan merupakan pencapaian anak berdasarkan indikator pencapaian perkembangan anak. Kedua bentuk laporan
p-ISSN: 2622-1993 e-ISSN: 2622-1586

tersebut selanjurnya direkapitulasi di laporan mingguan sebagaimana gambar di bawah ini:

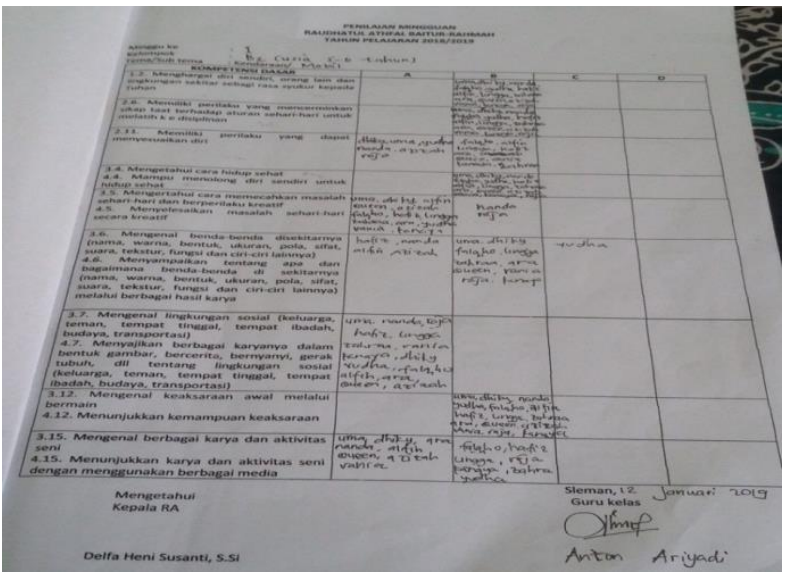

Gambar 2 Laporan Penilaian Mingguan RA Baitur-rahmah

Gambar 2 menjelaskan bahwa laporan mingguan di atas merupakan hasil dari rekapitulasi rata-rata hasil penilaian harian peserta didik dalam bentuk indikator pencapaian. Menurut bapak Anton, nama-nama yang dicantumkan adalah pencapaian perkembangan anak yang paling tinggi. Hasil laporan mingguan ini selanjutnya direkapitulasi dalam bentul laporan bulanan sebagaimana gambar di bawah ini. 
Al-Mudarris : Jurnal Ilmiah Pendidikan Islam Vol. 2, No. 1, Mei 2019, pp. 61-72

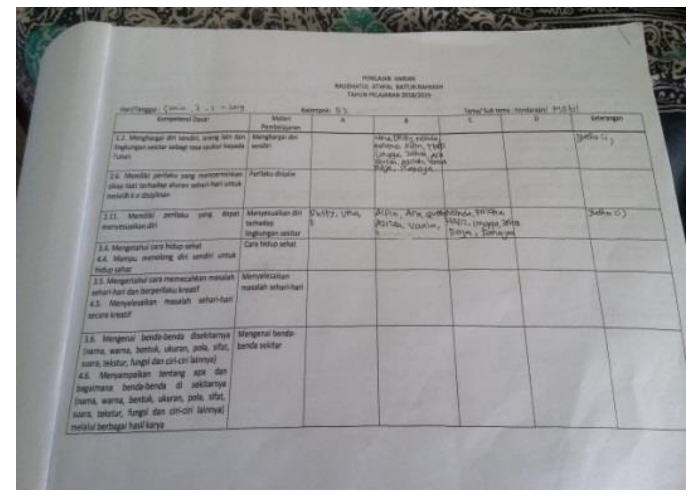

Gambar 3 Laporan Penilaian Bulanan RA Baitur-rahmah Menurut bapak Anton, laporan penilaian bulanan ini juga rekapitulasi penilaian mingguan.

\section{KESIMPULAN}

Model pembelajaran RA Baitur-Rahmah menggunakan pembelajaran kelompok dengan sudut pengaman (pengawasan, pengamatan guru) yang berdasarkan pada tema-tema. RA Baitur-Rahmah melaksanakan evaluasi dengan asesmen yang berkesinambungan. Asesmen autentik menilai kemampuan kognitif tingkat tinggi dalam melakukan melakukan sesuatu dikehidupan yang sesungguhnya atau real word setting. Asesmen autentik pada RA Baitur-Rahmah sudah diterapkan oleh para guru. Dalam hal ini, guru dalam kelas
p-ISSN: 2622-1993 e-ISSN: 2622-1586

sejumlah dua orang memiliki pekerjaan yang berbeda. Guru pertama melakukan asesmen dengan melihat produk yang telah dihasilkan oleh anak sesuai dengan indikator penilaian yang telah disediakan guru pada masing-masing kegiatan anak. Sedangkan guru kedua memiliki tugas untuk melihat bagaimana anak mengerjakan tugas tersebut, dengan artian, guru kedua bertugas melihat proses anak mengerjakan kegiatan tersebut.

Laporan penilaian pada RA Baitur-Rahmah terdiri dari laporan harian, mingguan, bulanan, dan semester. Laporan ini berisikan rentang nilai sesuai dengan capaian anak, kompetensi dasar yang sesuai dengan indikator pada tema yang dibawa, dan pada akhirnya mengelompokkan indikator sesuai dengan aspek perkembangan anak. 
Al-Mudarris : Jurnal Ilmiah Pendidikan Islam Vol. 2, No. 1, Mei 2019, pp. 61-72

\section{DAFTAR PUSTAKA}

Arifin, Zainal. (2012).Evaluasi Pembelajaran (Prinsip, Teknik, dan Prosedur.Bandung: Remaja Rosdakarya.

Gullo, Dominic F..(2005). Understanding Assesment and Evaluation in Early Childhood Education. Colombia University New York and London: Teacher College Press.

Hamalik, Oemar. (2003).Kurikulum dan Pembelajaran.Jakarta: Bumi Aksara.

Harun Rasyid. Pengembangan Instrumen Asesmen Autentik Bagi Perkembangan Anak Usia Dini pada Seminar Nasional Evaluasi Pendidikan Tahun 2014.
p-ISSN: 2622-1993

e-ISSN: 2622-1586

Khorida, Lilif dan Muhammad Fadlillah. (2013). Pendidikan Karakter Anak Usia Dini Konsep dan Aplikasi dalam PAUD. Yogyakarta: Ar-Ruzz Media.

Maryana, Rita, dkk. (2010). Pengelolaan Lingkungan

Belajar.Jakarta: Kencana Suprihatiningrum, Jamil. (2013).Strategi Pembelajaran Teori dan Aplikasi.Yogyakarta: Ar-Ruzz Media.

Trianto. (2011).Desain

Pengembangan Pembelajaran Tematik bagi Anak Usia DiniTK/RA \& Anak UsiaKelas Awal SD/MI. Jakarta: Kencana. Yusuf, A.Muri. (2015). Asesmen dan Evaluasi Pendidikan. Jakarta: Kencana. 